\title{
Nephelometry compared with differential antibody titre in routine rheumatoid factor measurements
}

\author{
R. K. KNIGHT AND M. H. PRITCHARD \\ From the Department of Rheumatology, University Hospital of Wales, Heath Park, Cardiff CF4 4XW
}

SUMMARY The comparative merits of agglutination techniques (differential agglutination titre (DAT)/latex slide test) and nephelometry for the routine measurements of IgM rheumatoid factors have been studied in this 2-part paper. The first part investigates the errors inherent in standard DAT measurements, and the second determines the rate of false positive results in an elderly nonrheumatoid population. It was found that the errors in agglutination techniques are due to differences in setting up the tests rather than in interpreting the results, and that the coefficient of variance was consistently around $20 \%$. Approximately 1 in 5 of DAT results have such a high error as to be clinically valueless. The false positive rate in the elderly nonrheumatoid population was only $2 \%$ with nephelometry compared with $9 \%$ on the latex slide test. A previous study had demonstrated the advantages of nephelometry over DAT in routine rheumatological use, showing not only greater reproducibility but also a more accurate positive detection rate than the DAT in rheumatoid arthritis. The results also suggest that the traditional spectrum of rheumatoid factors of low titre detectable in the general population is probably an artefact inherent in agglutination techniques and that a definitive cut-off point is more likely. As nephelometers are generally available in biochemistry laboratories there is much to recommended their routine use for the measurement of IgM rheumatoid factors.

Methods for measuring rheumatoid factors (IgM RF) in routine practice have not altered significantly since first introduced by Rose et al. in 1947. The method depends on the agglutination of gammaglobulin coated particles by the IgM RF in patient's serum which is diluted until no further agglutination is observed. One of the major drawbacks of this technique, however, is the poor sensitivity versus the selectivity ratio, and many minor modifications of the test have been introduced to try to overcome this. These include the substitution of latex particles for sheep red cells as a carrier or human gammaglobulin for a rabbit gammaglobulin as a coating material; but any increase in the number of false positives in the rheumatoid population has invariably been accompanied by an increase in the number of false positives in the nonrheumatoid group. ${ }^{12}$ It is frequently observed that titres found in individual patients over a period of time fluctuate substantially, but it has never been certain whether this is due to genuine physiological changes or technical errors in the method. It is clear therefore that, until IgM

Accepted for publication 10 July 1981.

Correspondence to Dr R. K. Knight. rheumatoid factors can be measured accurately, rapidly and reproducibly, the importance of these fluctuations cannot be ascertained, and indeed the question whether useful clinical information is obtained from such measurement cannot be resolved.

If the drawbacks outlined above are confined to agglutination techniques, it is possible they might be overcome by measuring IgM RF by alternative methods. In a previous paper $^{3}$ nephelometry (the measurement of protein concentration by light scattering) and DAT were compared in rheumatology outpatients, and the results suggested nephelometry had several advantages. This paper continues the study by, firstly, investigating the sources of error in the DAT technique, and, secondly, determining the false positive rate of IgM RF in the aged population by nephelometry. The technique of laser nephelometry is described elsewhere. ${ }^{3-6}$

\section{Materials and methods}

To determine the reproducibility of the DAT under normal laboratory conditions

Blood from 100 patients with rheumatoid arthritis 
was taken under routine aseptic precautions and the serum stored at $-20^{\circ} \mathrm{C}$ until ready for use. Patients were selected to include a substantial number with systemic features of the disease and with high levels of DAT on previous estimations. The measurements were carried out by 3 independent observers.

Observer $M$ set up and measured all 100 samples in 2 batches of 50 , reading each in duplicate. He then reset the same specimens a week later and again read the results in duplicate.

Observer $P$ set up samples 1-50, which were read independently by himself and by observer $S$, and this exercise was repeated a week later on the same samples.

Observer $S$ set up samples 51-100, which were read independently by himself and observer $P$, and this exercise was repeated in an identical manner the following week.

Each sample was thus read independently on 8 occasions and every combination of inter- and intraobserver error could be calculated both from reading the same experiment in duplicate (reading error) and for comparing readings on the same samples set up in an identical manner but a week apart (setting error). The method used to measure the DAT was the standard laboratory procedure in this hospital; the modification described by Cathcart and O'Sullivan ${ }^{7}$ of the original method described by Rose et al. ${ }^{8}$ The differences between readings obtained under different circumstances were tabulated and a coefficient of variance calculated together with the standard deviation. The percentage of results differing by 3 tube dilutions or more was also recorded, as it was considered that this degree of error would be unacceptable in clinical practice.

Percentage of false positive IgM RF in the nonrheumatoid elderly population

Serum was collected as in the previous survey from

Table 1 Errors observed in duplicate readings of the end point in DAT measurements: 50 samples per batch

\begin{tabular}{|c|c|c|c|c|c|}
\hline \multirow{2}{*}{ Experiment } & \multicolumn{5}{|c|}{ Reading errors } \\
\hline & $\begin{array}{l}\text { Mean } \\
\text { tube } \\
\text { error }\end{array}$ & $V_{c}$ & $\begin{array}{l}\text { Standard } \\
\text { deviation }\end{array}$ & $\begin{array}{l}\text { Max } \\
\text { tube } \\
\text { error }\end{array}$ & $\begin{array}{l}\% \text { deviating } \\
\text { by } \geqslant 3 \\
\text { tubes }\end{array}$ \\
\hline \multicolumn{6}{|c|}{$\begin{array}{l}\text { Read in duplicate by } \\
\text { Setter (M) }\end{array}$} \\
\hline Week 1 & $1 \cdot 3$ & $19 \cdot 5 \%$ & $1 \cdot 37$ & 3.0 & $1 \%$ \\
\hline Week 2 & 0.5 & $8.0 \%$ & 0.56 & $2 \cdot 0$ & $0 \%$ \\
\hline \multicolumn{6}{|c|}{$\begin{array}{l}\text { Set by }(S) \\
\text { Read by }(S) \text { and }(P)\end{array}$} \\
\hline Week 1 & 0.5 & $8.8 \%$ & 0.62 & $3 \cdot 0$ & $2 \%$ \\
\hline Week 2 & 0.4 & $9 \cdot 1 \%$ & 0.54 & $2 \cdot 0$ & $0 \%$ \\
\hline \multicolumn{6}{|l|}{ Set by (P) } \\
\hline
\end{tabular}

100 consecutive patients admitted to the acute geriatric units in the University Hospital of Wales and Llandough Hospital, Cardiff, without reference to patient's diagnosis. All patients were over 65 with a mean age of 75 . This group was chosen as previous population surveys showed the $65+$ age group have the highest percentage of positive results. ${ }^{9-11}$ A latex slide test (Hyland) was carried out on every sample, and the rheumatoid factor concentration measured by nephelometry in batches of approximately 30 samples. The results were then correlated with the patient's clinical diagnosis, and the false positive rate in the nonrheumatoid population calculated for each of the 2 methods.

\section{Results}

\section{SURVEY 1}

Errors in reading the DAT results could occur from differences in setting up the test (setting error) or from subjective differences between the 2 observers in reading the results (reading error). It has been assumed that the interpretation of results would be comparatively standard since all 3 technicians were working in the same laboratory, but an additional error could arise in theory if the end point was interpreted differently by different laboratories. The setting and reading errors observed in this survey are shown in Tables 1 and 2.

The reading error varied with the experience of the observers. Observer M, who was not an experienced laboratory technician, had a high reading error in the first 50 duplicate results $\left(C_{v} 19 \cdot 5 \%\right)$ but a negligible error in the second $50\left(C_{v} 8 \%\right)$. This is equivalent to a $\frac{1}{2}$ tube dilution and is of no clinical consequence. The other 2 observers, who were experienced technicians, showed very similar reading errors when they separately read the results of a single experiment. This suggests that in any one laboratory at least errors

Table 2 Errors observed in DAT measurements when set and read independently: 50 samples per batch

\begin{tabular}{|c|c|c|c|c|c|}
\hline \multirow[t]{2}{*}{ Experiment } & \multicolumn{5}{|c|}{ Setting errors } \\
\hline & $\begin{array}{l}\text { Mean } \\
\text { tube } \\
\text { error }\end{array}$ & $V_{c}$ & $\begin{array}{l}\text { Standard } \\
\text { deviation }\end{array}$ & $\begin{array}{l}\text { Max } \\
\text { tube } \\
\text { error }\end{array}$ & $\begin{array}{l}\% \text { deviating } \\
\text { by } \geqslant 3 \\
\text { tubes }\end{array}$ \\
\hline $\begin{array}{l}\text { Set and read by (S) } \\
\text { Week } 1 \mathrm{v} \text {. Week } 2\end{array}$ & 1.6 & $21 \cdot 3 \%$ & $1 \cdot 48$ & 6.0 & $20 \%$ \\
\hline $\begin{array}{l}\text { Set by (S) and read } \\
\text { by (P) } \\
\text { Week } 1 \text { v. Week } 2\end{array}$ & 1.4 & $19 \cdot 4 \%$ & $1 \cdot 36$ & $5 \cdot 0$ & $16 \%$ \\
\hline $\begin{array}{l}\text { Set and read by }(M) \\
\text { v. Set by }(P) \text { and } \\
\text { read by }(S) \\
\text { Week } 1 \\
\text { Week } 2\end{array}$ & $\begin{array}{l}1 \cdot 3 \\
1 \cdot 7\end{array}$ & $\begin{array}{l}34.5 \% \\
20.0 \%\end{array}$ & $\begin{array}{l}2.42 \\
1.4\end{array}$ & $\begin{array}{l}7 \cdot 5 \\
7 \cdot 0\end{array}$ & $\begin{array}{l}42 \% \\
18 \%\end{array}$ \\
\hline
\end{tabular}


of end point interpretation are insignificant but that experience is a major factor in the reliability of the test.

The setting errors were estimated in 2 ways. Firstly, the samples being set up and read by different observers and, secondly, being set up by the same observer but a week later. The errors were found to be remarkably consistent, the $\mathrm{C}_{\mathrm{v}}$ varying from $19 \cdot 4$ to $21 \cdot 3 \%$, although it rose substantially when observer M's first 50 readings were included. It is clear, therefore, that even under test circumstances with experienced technicians a mean error of $20 \%$ of the results can be expected due to variations in the setting up of the test. A more serious finding for routine clinical practice, however, was the high percentage of results which differed by 3 tubes dilution or more. Once again this was highest when including observer M's first 50 results, when it reached $42 \%$, but with experience this fell to the same level as comparisons between the other 2 observers and was found to vary between 16 and $20 \%$. This means that in any one batch of DAT results almost 1 result in 5 is sufficiently unreliable as to be of no clinical value. The implications of this in long-term studies on the relevance of DAT measurements in rheumatoid patients are considerable, as it suggests the fluctuation seen in such surveys ${ }^{12}$ is almost certainly artefactual, and this high degree of error makes it impossible to correlate the DAT with other parameters with any degree of accuracy.

\section{SURVEY 2}

The results of this study are tabulated in Fig. 1. Of the 100 patients tested 10 gave positive results on the conventional latex slide test (Hyland). Eight of these . 10 patients had low nephelometry scores and had no evidence on clinical or radiological grounds to suggest that they had rheumatoid arthritis. The other 2 latex-positive patients had high nephelometry scores. One of these had classical rheumatoid arthritis of many years' standing and current clinical activity; the other had complained of musculoskeletal symptoms for many years, but this had been investigated in another hospital and the clinical details were not available. In the latex-negative group one patient had a high nephelometry score. He was found on investigation to be suffering from a toxic multinodular goitre with no evidence of rheumatoid arthritis on clinical grounds.

Of the 89 latex-negative patients with low nephelometry scores, 2 were found to have an erosive arthropathy. One of these patients had been treated for seropositive rheumatoid disease but after treatment with gold, cyclophosphamide, and azathioprine she had become seronegative, and clinically the arthritis was in full remission. The other patient, although

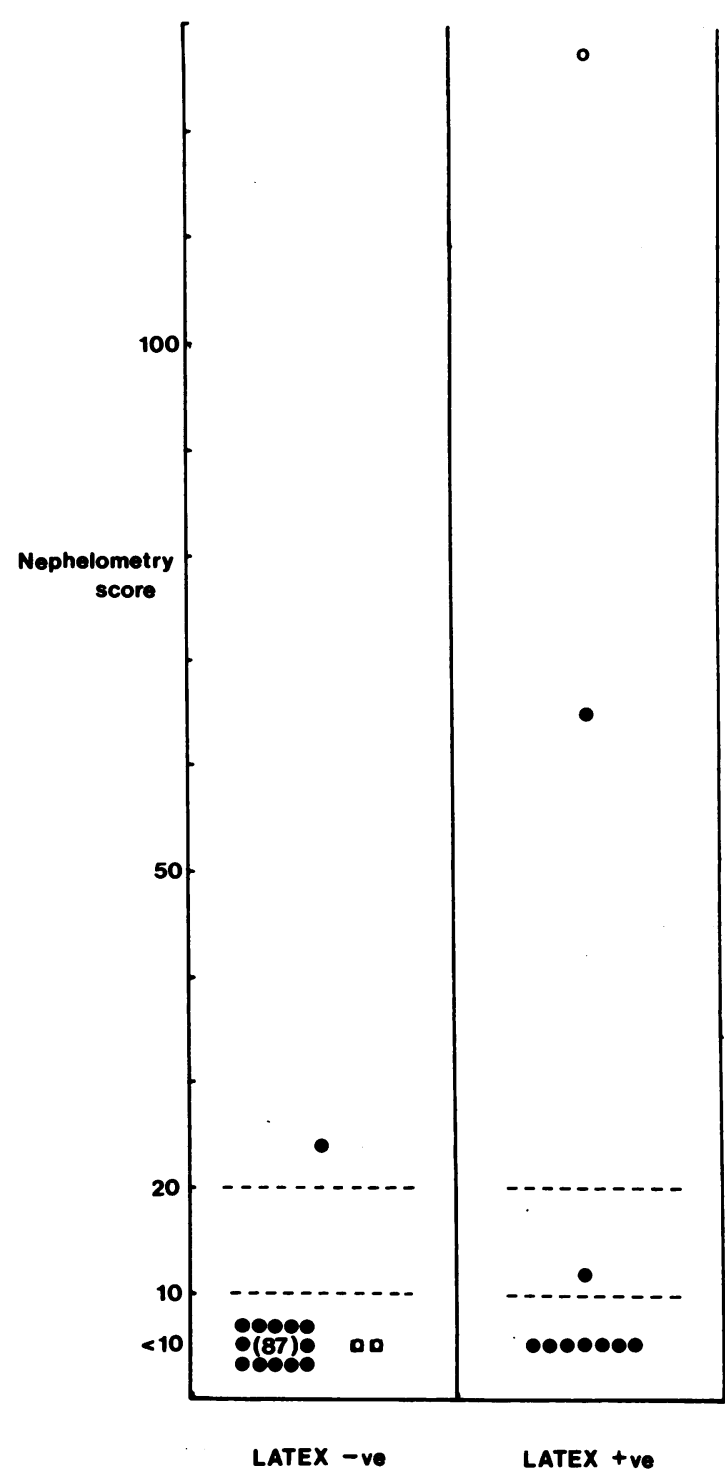

Fig. 1 Nephelometry scores in 100 consecutive admissions to the acute geriatric unit. = No arthropathy.

$\bigcirc=$ Rheumatoid arthritis. $\square=$ Radiological erosions, no clinical activity.

radiologically erosive, had been persistently seronegative and was symptom-free. She had been admitted for investigation of ulcerative colitis.

There was therefore a $9 \%$ incidence of false Positive results with a latex test and $2 \%$ with the laser nephelometer. One of these 2 was also latex-positive; both methods failed to detect 2 patients with erosive arthritis, one of whom was known to be rheumatoid. It is apparent from the previous study ${ }^{3}$ that 
nephelometry did not give positive results on patients clinically and biochemically in remission, and these 2 patients fitted this description.

\section{Discussion}

It is disappointing that after more than 30 years of routine use in clinical practice $\operatorname{IgM} \mathrm{RF}$ tests (DAT/SCAT/RA latex/FII) have still to prove that they are of much more value than screening tests for rheumatoid disease. Numerous restrospective studies reported over the last 20 years have shown that the presence of IgM RF in rheumatoid disease is a poor prognostic indicator and that conversely a persistently seronegative patient is likely to do better. ${ }^{12-16}$ The differences, however, especially in the early studies, are likely to be unrealistically great, as it is probable that many of the patients in the seronegative control group did not have rheumatoid disease anyway. All the papers quoted are retrospective, and their results, being statistical analyses of groups, have no predictive value in individual cases. Only one paper ${ }^{16}$ attempted to correlate the rheumatoid factor titre with clinical features of rheumatoid disease. They found that statistically significant correlations could be made in retrospect between the maximum rheumatoid factor titres found in the first year after diagnosis and certain clinical parameters observed at follow-up between 8 and 14 years later. However, Lloyd et al. ${ }^{17}$ failed to show any correlation between IgM RF titre and 10 other clinical and biochemical parameters in a comprehensive survey of 100 patients.

DATs as currently measured are too elaborate to be a convenient screening test, yet the degree of elaboration is both inaccurate and of doubtful clinical significance. Apart from the technical inaccuracies a further problem exists in the interpretation of lowtitre results, and that is the belief that rheumatoid factor titres exist in the normal population as a continuum without a clear cut-off point between the normal and rheumatoid groups. ${ }^{10}$ Ball $^{18}$ proposed that the titres of $1 / 32$ satisfactorily divided pathologically high titres found in rheumatoid disease and the low titres frequently found in the normal population. This was confirmed by Ball and Lawrence, and is still the generally accepted titre in clinical practice today..$^{10}$ The problems of interpretation arise because many rheumatoid patients have low rheumatoid factor titres by agglutination methods, and the adoption of a titre of $1 / 32$ as a cut-off point excludes these from being considered seropositive. Such patients are then often erroneously given a better prognosis, even though they are clinically indistinguishable from seropositive patients.

When the results of the previous and present study are considered together, it is clear that nephelometry does not confirm the presence of this continuum, and this suggests that it may be an artefact due to a nonspecific reaction in the older agglutination techniques. Other evidence supports this proposal. Heimer et al. $^{19}$ found that by latex testing as many as $46 \%$ of the elderly population gave positive results. They were convinced that these were not genuine rheumatoid factors and entitled them 'globulins resembling rheumatoid factors' instead. This suggests that nonspecific agglutinations are detectable by, and can interfere with, agglutination methods, but refinements of the tests to reduce these have unfortunately invariably reduced the positive detection rate in the rheumatoid patients as well. Hay et $a l .{ }^{20}$ measured rheumatoid factors by solid phase radioimmunoassay, a method which gives an accurate measurement of the concentration of rheumatoid factors, and although they have not included a large normal population the results shown for their nonrheumatoid patients were quite distinct from the rheumatoid ones-again suggesting that there is no genuine continuum of rheumatoid factor titres in the population. If this concept of a continuum with its high cut-off point of $1 / 32$ could be abandoned, a more definite division between normal and rheumatoid populations could be determined and the cut-off point lowered to give a smaller proportion of rheumatoid patients being considered seronegative.

Although agglutination tests involving latex particles generally have a higher rate of false positives in the normal population than sheep cell based tests, they remain a convenient and quick screening test for rheumatoid disease, since they can be carried out on a slide in less than 2 minutes with a minimum of technical expertise. Significantly high false positive rates, however, often mean that a confirmatory test is required to make the final diagnosis. Nephelometry is advantageous in this situation, as the false positive rate is low enough not to require further confirmatory test. Similarly Pritchard and Jobbins ${ }^{3}$ have shown that the percentage of positive results in the rheumatoid population is significantly better than the DAT. An arbitrary cut-off point of 20 units was chosen when comparing nephelometry with DAT as this gave the best agreement with the accepted DAT titre of $1 / 32$. However, with the absence of any obvious continuum of rheumatoid factors by this method the cut-off point could be reduced to 10 units and include only one more patient (a woman with ankylosing spondylitis) in the nonrheumatoid population survey.

Agglutination tests have stayed in use for 30 years because of the lack of alternatives. However, other methods have been evaluated. Hay et al. ${ }^{20}$ and Koopman and Schrohenloher ${ }^{21}$ have described solid 
phase radioimmunoassay techniques which involve the binding of rheumatoid factors to rabbit immunoglobulins linked to plastic tubes. This method is accurate and has the advantage of giving the results in concentrations of rheumatoid factors of all 3 classes to be detected. The technique, however, is elaborate, requires a considerable degree of technical expertise, and is still perhaps more useful for research purposes than routine clinical practice. Nephelometry by contrast is simple and rapid. Using the semiautomated nephelometer, one technician took $2 \frac{1}{2}$ hours to set up and read a batch of nephelometry samples-a considerable saving over the 5 hours' time normally required to set up and read the equivalent number of DATs. This time would be reduced even further with a fully automated machine.

With the elimination of the high level of technical errors and with the adoption of a clear cut-off point between normal and rheumatoid population, it might now be possible to answer the question posed at the beginning: Does the measurement of the actual concentration of IgM RF have any clinical value?

The DAT error experiments were organised by Dr Meurig Williams. We are grateful to Professor Pathy and his staff for allowing us to study their patients in the geriatric unit.

\section{References}

1 Waller M. Methods of measurement of rheumatoid factor. Ann N Y Acad Sci 1969; 168: 15-20.

2 Zutshi D W, Reading C A, Epstein W V, Ansell B M, Holborow E J. FII haemagglutination test for serum antigammaglobulin factors in arthritides seropositive and seronegative by other tests. Ann Rheum Dis 1969; 28: 289-99.

${ }^{3}$ Pritchard M H, Jobbins K. Nephelometry v. differential agglutination titre in the measurement of rheumatoid factors.J Clin Pathol 1981; 34: 396-9.

4 Virella G, Waller M, Fudenberg H H. Nephelometric method for determination of rheumatoid factor. $J$ Immunol Methods 1978; 22: $247-51$
${ }^{5}$ Finley P R, Hicks J, Williams R J, Hinlicky J, Lichti D A. Rate nephelometric measurement of rheumatoid factor in serum. Clin Chem 1979; 25: 1909-14.

${ }^{6}$ Weinblatt M E, Schur P H. Rheumatoid factor detection by nephelometry. Arthritis Rheum 1980; 23: 777-9.

7 Cathcart E S, O'Sullivan W C. Standardisation of the sheep cell agglutination test: the use of pooled reference sera and haemagglutination trays. Arthritis Rheum 1965; 8: 530-7.

8 Rose H M, Ragan C, Pearce E, Lipman M O. Differential agglutination of normal and sensitised sheep erythrocytes by sera of patients with rheumatoid arthritis. Proc Soc Exp Biol Med 1948; 68: $1-6$.

${ }^{9}$ Kellgren J H, Ball J. Clinical significance of the rheumatoid serum factor. $\mathrm{Br}$ Med J 1959; i: 523-31.

10 Ball J, Lawrence J S. Epidemiology of the sheep cell agglutination test. Ann Rheum Dis 1961; 20: 235-43.

1 Waller M, Toone E C, Vaughan E. Study of rheumatoid factor in a normal population. Arthritis Rheum 1964; 7: 513-20.

12 Ragan C, Farrington E. The clinical features of rheumatoid arthritis-prognostic indices. JAMA 1962; 181: 663-7.

${ }^{13}$ Otten H A, Westendorp Boerma F. Significance of the WaalerRose test, streptococcal agglutination and antistreptolysin titre in the prognosis of rheumatoid arthritis. Ann Rheum Dis 1959; 18: 24-8.

14 Duthie J J R, Brown P E, Truelove L H, Baragar F D, Lawrie A J. Course and prognosis in rheumatoid arthritis-a further report. Ann Rheum Dis 1964; 23: 193-202.

is Cats A, Hazevoet H M. Significance of positive tests for rheumatoid factor in the prognosis of rheumatoid arthritis. Ann Rheum Dis 1970; 29: 254-60.

${ }^{16}$ Jacoby R K, Jayson M I V, Cosh J A. Onset, early stages and prognosis of rheumatoid arthritis: a clinical study of 100 patients with 11 year follow-up. Br Med J 1973; ii: 96-100.

${ }^{17}$ Lloyd K N, Williams P I, Williams M. Reliability of tests for rheumatism-pitfalls of screening tests and reproducibility. Abs 16: XIV Int Congress of Rheumatology. San Francisco, 1977.

${ }^{18}$ Ball $\mathrm{J}$. Serum factor in rheumatoid arthritis agglutinating sensitised sheep red cells. Lancet 1950; ii: 520-3.

19 Heimer R, Levin F M, Rudd E. Globulins resembling rheumatoid factor in serum of the aged. Am J Med 1963; 35: 175-81.

${ }^{20}$ Hay F C, Nineham L, Roitt I M. Routine assay for detection of IgG and IgM antiglobulins in seronegative and seropositive rheumatoid arthritis. Br Med J 1975; iii: 203-4.

${ }^{21}$ Koopman W J, Schrohenloher R E. A sensitive radioimmunoassay for quantitation of IgM rheumatoid factor. Arthritis Rheum 1980; 23: 302-8. 